\title{
Safety Assessment of Polycyclic Aromatic Hydrocarbons (PAHs) in Cold Smoked Fish (Mugil Cephalus) Using GC-MS
}

\section{Hafez NE ${ }^{1 *}$, Awad $\mathbf{A M}^{1}$, Ibrahim $\mathrm{SM}^{2}$ and Mohamed $\mathrm{HR}^{2}$}

${ }^{1}$ Department of Food Science and Technology, Faculty of Agriculture, El-Fayoum University, Egypt

${ }^{2}$ Fish Processing and Technology Laboratory, Fisheries Division, National Institute of Oceanography and Fisheries, Egypt

\begin{abstract}
This work was planned to determine the safety level of polycyclic aromatic hydrocarbons (PAHs) in cold smoked mullet fish obtained from two fish farms (A and B) localized at El-Fayoum Governorate, Egypt during August 2015. PAHs components were determined by GC-MS. Results showed that total of PAHs components was 28.8 and $5 \mathrm{ppb}$ in both smoked fish products (A and $B$ ), respectively. Also, low molecular weight (LMW) of PAHs was found especially in smoked fish (A), followed by medium molecular weight (MMW) and however high molecular weight (HMW) was not detectable. Levels of Benzo [a] Pyrene (B \{a\} $P)$ equivalent were 0.051 and 0.005 in products $(A$ and $B)$, respectively. However, PAH4 $(B a P+C H R+B a A+B b F)$ and PAH8 (Benzo (a) anthracene, Chrysene, Dibenzo ( $a, h)$ anthracene, Benzo ( $g, h$, i) perylene, Benzo (b) Fluoranthene, Benzo (k) fluoranthene, Benzo (a) Pyrene, Indeno (1, 2, 3-c, d) Pyrene) were not detectable. Also, categories of PAHs concentration are considered a minimally contaminated $(10$ to $99 \mu \mathrm{g} / \mathrm{kg}$ ) and not contaminated $(<10 \mathrm{ppb})$ compared with the maximum recommended levels. Based on our results, it could be concluded that Benzo (a) pyrene compound was not detectable in all smoked samples which are considered as a safe product for human consumption.
\end{abstract}

Keywords: Fish; Smoking; PAHs; GC-MS

\section{Introduction}

Contamination of food by polycyclic aromatic hydrocarbons (PAHs) can be resulted from food processing at high temperature such as frying, smoking or roasting Codex [1-3]. There are many parameters limited the amounts of PAHs in food such as composition of the smoke, technology used in smoking, combustion temperature, type of wood, and exposure of the edible parts to the smoke [3-5]. The ranges of MW could be divided into three classes; $152 \mathrm{~g} / \mathrm{mol}$ to $178 \mathrm{~g} / \mathrm{mol}, 202$ and 228 $\mathrm{g} / \mathrm{mol}$ to $278 \mathrm{~g} / \mathrm{mol}$ of low, medium and high MW, respectively [6,7]. Seven of the PAHs have been considered human carcnogens; benzo (a) anthracene, benzo (b) fluoranthene, benzo (k) fluoranthene, chrysene, benzo (a) pyrene, dibenzo $(a, h)$ anthracene, and indeno $(1,2,3-c, d)$ pyrene. Therefore, this study was designed to determine the safety level of PAHs in cold smoked mullet fish samples that were obtained during August 2015 from two fish farms localized at El-Fayoum governorate, Egypt (Figure 1).

\section{Materials and Methods}

\section{Fish samples}

Mullet fish (Mugil cephalus) samples were obtained after directly catch from two fish farms (A and B). The main resources of irrigation water were industrial for A and agricultural discharge for B during August 2015 at El-Fayoum governorate. They were transported within two hours using ice box to Fish Processing and Technology Lab, Shakshouk Station for Water Resource, National Institute of Oceanography and Fisheries (NIOF), Egypt. Average of weight 453.3 gm $\pm 51.7 \mathrm{gm}$ and length $35 \mathrm{gm} \pm 3 \mathrm{~cm}$ for raw samples from Farm A (Industrial discharge) also, average weight and length of raw mullet samples from Farm B (Agricultural discharge) are $526.6 \mathrm{gm} \pm 18 \mathrm{gm}$ and $38 \mathrm{~cm} \pm 2 \mathrm{~cm}$ respectively.

\section{Smoking process and source of PAHs}

After that, chilled whole fish samples were washed carefully with tap water, soaked in $10 \%$ brined solution for $2 \mathrm{hrs}$, rinsed with tap water for $1 \mathrm{~min}$, semi-dried at $250^{\circ} \mathrm{C}$ for two hrs, traditional cold smoked at $35^{\circ} \mathrm{C}$ to $45^{\circ} \mathrm{C}$ for 8 to $10 \mathrm{hrs}$, using sawdust and finally cooled under ambient temperature.

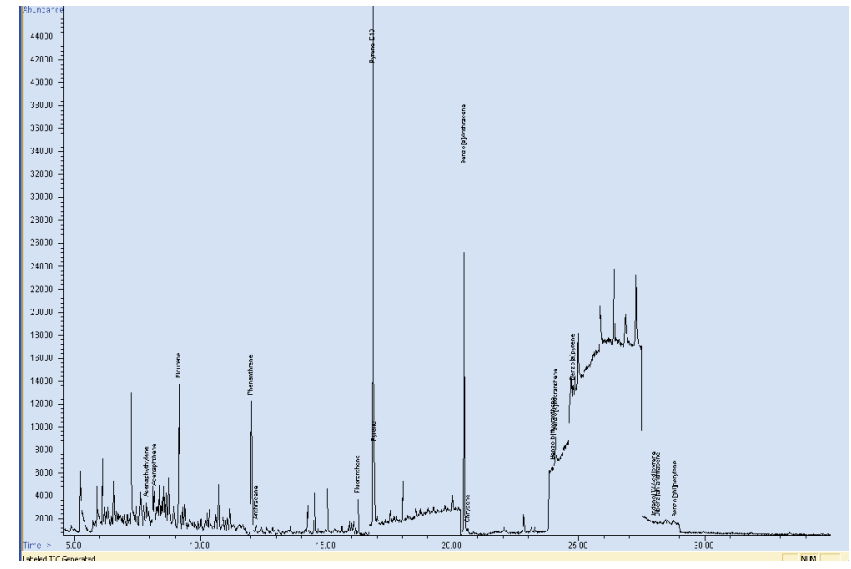

Figure 1: GC-MS chromatogram of smoked mullet fish (farm A).

\section{Analytical methods}

The edible of smoked mullet fish products was manually separated, homogenized, packed in polyethylene bags and then stored in a freezer at $-20^{\circ} \mathrm{C}$ till analysis.

PAHs determination: PAHs were determined at Central Laboratory of Residue Analysis of Pesticides and Heavy Metals in Food

${ }^{*}$ Corresponding author: Hafez NE, Department of Food Science and Technology, Faculty of Agriculture, El-Fayoum University, Egypt, Tel: 084 6356731; E-mail: m_fathy8789@yahoo.com

Received July 17, 2017; Accepted August 04, 2017; Published August 11, 2017 Citation: Hafez NE, Awad AM, Ibrahim SM, Mohamed HR (2017) Safety Assessment of Polycyclic Aromatic Hydrocarbons (PAHs) in Cold Smoked Fish (Mugil Cephalus) Using GC-MS. J Food Process Technol 8: 688. doi: 10.4172/2157-7110.1000688

Copyright: $\odot 2017$ Hafez NE, et al. This is an open-access article distributed under the terms of the Creative Commons Attribution License, which permits unrestricted use, distribution, and reproduction in any medium, provided the original author and source are credited. 


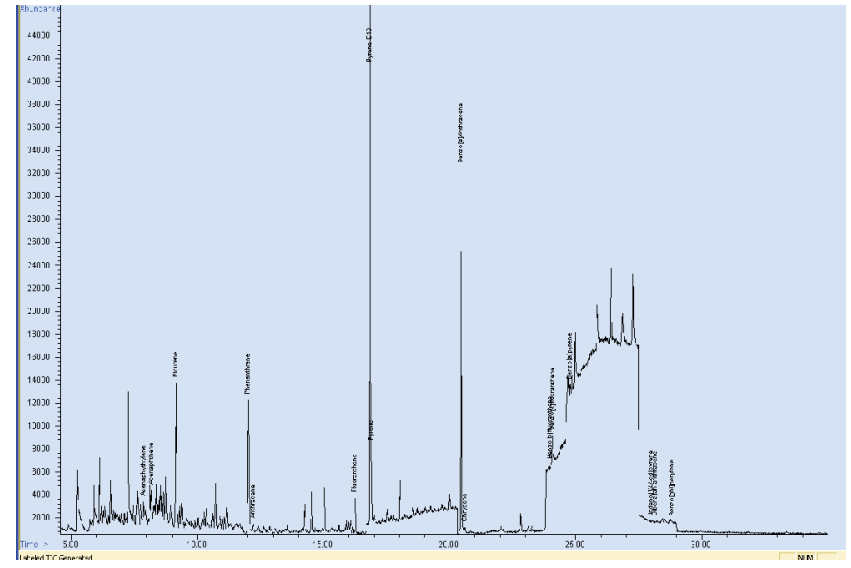

Figure 2: GC-MS chromatogram of mullet fish ( farm B).

\begin{tabular}{|c|c|c|c|c|c|}
\hline \multirow{2}{*}{ Compound } & \multirow{2}{*}{ Abbrev. } & \multirow{2}{*}{ Mw } & \multirow{2}{*}{ Rings } & \multicolumn{2}{|c|}{ Concentration (ppb) } \\
\cline { 4 - 6 } & & & & Farm (A) & Farm (B) \\
\hline Chrysene & CHR & 228 & 4 & ND & ND \\
\hline Anthracene & ANT & 178 & 3 & 2.8 & ND \\
\hline Acenaphthene & ACE & 154 & 3 & ND & ND \\
\hline Benzo(b)fluoranthene & BbF & 252 & 5 & ND & ND \\
\hline Benzo(k)fluoranthene & BkF & 252 & 5 & ND & ND \\
\hline Dibenzo(a,h)anthracene & DahA & 278 & 5 & ND & ND \\
\hline Fluorene & FLU & 166 & 3 & 6.6 & ND \\
\hline Naphthalene & NA & 128 & 3 & ND & ND \\
\hline Benzo(a)pyrene & BaP & 252 & 5 & ND & ND \\
\hline Benzo(g,h,i)perylene & BghiP & 276 & 6 & ND & ND \\
\hline Indeno(1,2,3,cd)pyrene & IcdP & 276 & 6 & ND & ND \\
\hline Acenaphthylene & ACY & 152 & 3 & ND & ND \\
\hline Fluoranthene & FLA & 202 & 4 & 3.3 & 2.1 \\
\hline Pyrene & PYR & 202 & 4 & 4.6 & 2.9 \\
\hline Benzo(a)anthracene & BaA & 228 & 4 & ND & ND \\
\hline Phenanthrene & PHE & 178 & 3 & 11.5 & ND \\
\hline \multicolumn{2}{|c}{$\Sigma 16 P A H s$} & & & 28.8 & 5 \\
\hline
\end{tabular}

Table 1: Molecular weight (MW), number of rings and concentration of PAHs in smoked mullet samples.

(QCAP), Agricultural Research Centre. Cairo, Egypt as described by Forsberg et al. [8], Smoker et al. [9] and Khorshid et al. [10].

$\mathrm{B}\{\mathbf{a}\} \mathbf{P}$ equivalent: The $\mathrm{B}\{\mathrm{a}\} \mathrm{P}_{\text {eq }}$ was calculated as the $\Sigma \mathrm{B}\{\mathrm{a}\} \mathrm{P}_{\text {eqi }}$ value for individual PAHs. The $\mathrm{B}\{\mathrm{a}\} \mathrm{P}_{\text {eqi }}$ calculated as the following equation [11]:

$$
B a P_{e q}=\sum\left(B a P_{e q i}\right)=\sum\left(C_{P A H i} \times T E F_{P A H i}\right)
$$

$\mathrm{C}_{\mathrm{PAHi}}$ : Concentration of each PAH in the sample,

$\mathrm{TEF}_{\mathrm{PAHi}}$ : Toxic equivalency factor for each individual PAH.

Statistical analysis: The results obtained were analyzed statistically using the least significant difference test $(\mathrm{LSD})$ at $(\mathrm{P} \leq 0.05)$ and were expressed as Mean \pm SD using SPSS 16 for windows.

\section{Results and Discussion}

As previous mentioned that raw mullet samples were obtained from different fish farms based on irrigation main resources; farm (A) was dependent on industrial discharge and localized at eastern Fayoum governorate farms whereas farm (B) was dependent on agriculture discharge and localized at Qarun lake farms (Figure 2).

\section{Polycyclic aromatic hydrocarbons (PAHs)}

Table 1 shows the PAHs concentration of cold smoked mullet fish flesh. 16 components of PAHs were detected in edible part of investigated products. Concentrations of ANT, FLA, PYR, FLU and PHE were 2.8, 3.3, 4.6, 6.6 and $11.5 \mathrm{ppb}$, respectively in smoked fish farm (A).

Farm (A): Industrial discharge. Farm (B): Agricultural discharge. Mw: Molecular weight.

In the other batch, FLA and PYR levels were 2.1 and $2.9 \mathrm{ppb}$, respectively in smoked fish farms (B). The PAHs have been grouped according to its molecular weights, we found that the high MW components of PAHs (228 g/mol to $278 \mathrm{~g} / \mathrm{mol})$, were Benzo (a) anthracene, Benzo (b) fluoranthene, Benzo (k) fluoranthene, Benzo (j) fluoranthene, Benzo (e) pyrene, Benzo (a) Pyrene, Benzo (ghi) perylene, dibenzo (h) anthracene, chrysene, cyclopenta (cd) pyrene, indo (1, 2, 3-c, d) Pyrene, and anthranthrene. The medium MW components (202 $\mathrm{g} / \mathrm{mol}$ ) were fluoranthene and pyrene. The low molecular weights (152 $\mathrm{g} / \mathrm{mol}$ to $178 \mathrm{~g} / \mathrm{mol}$ ) included naphthalene, Acenaphthylene, acenaphthene, fluorene, anthracene and phenanthrene. Total of PAHs were 28.8 and $5 \mathrm{ppb}$ in both smoked fish farms (A) and (B), respectively. In addition, rings number of PAHs in smoked fish farm (A) ranged from 3 to 4 rings and its MW ranged from 166 to 178 whereas in case of farm (B) only 4 rings and 202 as MW were found. Comparison of fish species smoked as fillets and as whole fish illustrated that the level of PAHs was higher for smoked fillets in comparison with the same fish species smoked as a whole fish.

\section{Category of PAH concentration}

Categories of concentration of PAH are considered a minimally contaminated (10 to $99 \mathrm{ppb})$ and not contaminated $(<10 \mathrm{ppb})$ compared with recommended levels as set by Soares-Gomes et al. [12]. Concentrations of PAH were 28.8 and $5.0 \mu \mathrm{g} / \mathrm{kg}$ in smoked fish farms (A) and (B), respectively. Based on these results, Farm A (Industrial discharge) and B (Agricultural discharge) classified as minimally contaminated and Not contaminated respectively.

\section{Molecular weight of PAHs in smoked fish}

Also, Table 2 exhibits the molecular weight (MW) of PAHs in smoked mullet fish. The total concentration of the low molecular weights (LWM) of PAHs was higher than the medium molecular weights (MMW) in smoked fish farm (A). The high concentration of LWM in smoked fish farm (A) was $20.9 \mathrm{KDa}$. In other side, total concentration of medium molecular weights of PAHs was $5 \mathrm{KDa}$. Lipophilic nature of the PAHs and fish's skin may be make better protection from the HMW-PAHs than LMW as reported by Mohammadi et al. [13]. In addition, results showed that there is no found a HMW-PAHs in different smoked fish farms either (A) or (B). In all products, HMWPAHs were below the limit of quantification or not detectable.

\section{Toxic equivalent factors (TEFs) and $B$ \{a $P$ equivalent of PAHs}

TEF is an estimate of the relative toxicity of individual PAH fraction

\begin{tabular}{|c|c|c|c|}
\hline Fish farm & HMW & MMW & LMW \\
\hline A & - & 7.9 & 20.9 \\
\hline B & - & 5 & - \\
\hline Farm (A): Industrial discharge. & Farm (B): Agricultural discharge \\
\hline
\end{tabular}

Table 2: Molecular weight (MW) of PAHs in cold smoked fish. 
Citation: Hafez NE, Awad AM, Ibrahim SM, Mohamed HR (2017) Safety Assessment of Polycyclic Aromatic Hydrocarbons (PAHs) in Cold Smoked Fish (Mugil Cephalus) Using GC-MS. J Food Process Technol 8: 688. doi: 10.4172/2157-7110.1000688

Page 3 of 4

compared to benzo(a) pyrene. The toxic equivalent factors (TEFs) and $\mathrm{B}$ [a] P Equivalent of PAHs in smoked mullet fish are present in Table 3. Concentrations of phenanthrene, flourene, pyrene, fluoranthene and anthracene in smoked fish farm (A) were 11.5, 6.6, 4.6, 3.3 and 2.5 $\mathrm{ppb}$, respectively and total B [a] P Equivalent was 0.051 . On the other side, concentrations of pyrene and fluoranthene in smoked fish farm (B) were 2.9 and $2.1 \mathrm{ppb}$, respectively and total B [a] P Equivalent was 0.005 .

\section{Benzo [a] pyrene (BaP), PAH4 and PAH8}

In this study the PAH4 (the sum of BaP, chrysene, benz [a] anthracene and benzo [b] fluoranthene) and PAH8 \{Benzo (a) anthracene, Chrysene, Dibenzo (a, h) anthracene, Benzo (g, h, i) perylene, Benzo (b) Fluoranthene, Benzo (k) fluoranthene, Benzo (a) Pyrene, Indeno (1, 2, 3-c, d) Pyrene\} were not detected in smoked fish samples too. So, in the current study, cold smoked products are safety for human consumption because $\mathrm{BaP}$ did not detect comparing to the maximum permissible limit $2 \mathrm{ppb}$ as set by the European Commission Regulation (OJEU, 835/2011) [14]. These results are in accordance to the findings by El-Lahamy et al. [15] who reported that BaP not detected in cold and hot smoked catfish fillets.

\section{Sources and assessment of PAHs}

Table 4 shows that source characterization and assessment of

\begin{tabular}{|c|c|c|c|c|c|}
\hline \multirow[b]{2}{*}{ Compound } & \multirow[b]{2}{*}{ TEF } & \multicolumn{2}{|c|}{ Farm (A) } & \multicolumn{2}{|c|}{ Farm (B) } \\
\hline & & $\begin{array}{l}\text { PAHs }(\mu \mathrm{g} / \\
\mathrm{kg})\end{array}$ & $\mathrm{BaP}_{\text {eqi }}$ & $\begin{array}{c}\text { PAHs ( } \mu \mathrm{g} / \\
\mathrm{kg})\end{array}$ & $\mathrm{BaP}_{\text {eqi }}$ \\
\hline Naphthalene & 0.001 & ND & - & ND & - \\
\hline Acenaphthylene & 0.001 & ND & - & ND & - \\
\hline Acenaphthene & 0.001 & ND & - & ND & - \\
\hline Fluorene & 0.001 & 6.6 & 0.0066 & ND & - \\
\hline Phenanthrene & 0.001 & 11.5 & 0.0115 & ND & - \\
\hline Anthracene & 0.01 & 2.5 & 0.025 & ND & - \\
\hline Fluoranthene & 0.001 & 3.3 & 0.0033 & 2.1 & 0.0021 \\
\hline Pyrene & 0.001 & 4.6 & 0.0046 & 2.9 & 0.0029 \\
\hline Benzo(a)anthracene & 0.1 & ND & - & ND & - \\
\hline Chrysene & 0.01 & ND & - & ND & - \\
\hline Benzo(b)fluoranthene & 0.1 & ND & - & ND & - \\
\hline Benzo(k)fluoranthene & 0.1 & ND & - & ND & - \\
\hline Benzo(a)pyrene & 1 & ND & - & ND & - \\
\hline Indeno(1,2,3,c)pyrene & 0.1 & ND & - & ND & - \\
\hline $\begin{array}{l}\text { Dibenzo(a,h) } \\
\text { anthracene }\end{array}$ & 1 & ND & - & ND & - \\
\hline Benzo(g,h,i)perylene & 0.01 & ND & - & ND & - \\
\hline$\sum\left(\mathrm{BaP}_{\text {eqi }}\right)$ & & & 0.051 & & 0.005 \\
\hline
\end{tabular}

TEF: Toxic equivalent factor; $\mathrm{BaP}_{\mathrm{a}}$ : $\mathrm{B}$ [a] $\mathrm{P}$ equivalent; Farm (A): Industrial discharge; Farm (B): Agricultural discharge

Table 3: Toxic Equivalent factors (TEFs) and B [a] P Equivalent of PAHs in smoked mullet fish.

\begin{tabular}{|c|c|c|c|}
\hline \multirow{2}{*}{ Source of PAHs } & \multicolumn{2}{|c|}{ PAH Ratios } \\
\cline { 2 - 4 } & [An/(An + Phen)] & {$\left[\begin{array}{cl}\text { [FI (FI + Py)] } \\
\mathbf{1 7 8}\end{array}\right.$} \\
\hline \multicolumn{2}{|c|}{ Wood combustion } & $>0.10$ & $>0.5$ \\
\hline \multicolumn{2}{|c|}{ Petroleum } & $<0.10$ & 0.40 \\
\hline \multirow{2}{*}{ Saw dust } & Farm A & 0.19 & 0.41 \\
\cline { 2 - 4 } & Farm B & ND & 0.42 \\
\hline
\end{tabular}

[An/(An+Phen)]: anthracene plus phenanthrene. [Fl/(Fl+Py)]: fluoranthene to fluoranthene plus pyrene. Farm (A): Industrial discharge. Farm (B): Agricultural discharge.

Table 4: Sources and assessment of PAHs comparing with the previous reference.
PAHs comparing with the previous references. It is well known that the sawdust wood was used as source of PAHs in this work as mentioned above (material and methods part). Results showed that the ratio of anthrancene to anthracene plus phenanthrene [An/(An+Phen)] was 0.19 in case of product obtained from farm A while it was not detected in farm B. This indicates that the wood combustion is the main source of PAHs compared with the mass 178 . $[\mathrm{An} /(\mathrm{An}+\mathrm{Phen})]$ ratio $<0.10$ usually is referred to petroleum while a ratio $>0.10$ indicates dominance of combustion [16-18]. The $[\mathrm{Fl} /(\mathrm{Fl}+\mathrm{Py})]$ ratio also ranged from 0.41 to 0.42 in farm $A$ and $B$ products, respectively. The ratios ranged between 0.4 and 0.5 the refers to some amount of fossil fuel combustion sources (vehicular, fat and crude oil) of PAHs [19-22].

\section{Conclusion}

In conclusion, the safety of smoked fish has been controlled by measuring benzo (a) pyrene level, which is one of the most carcinogenic PAHs. European Commission has limited the maximum acceptable concentrations of benzo (a) pyrene at $2 \mathrm{ppb}$ for smoked fish and smoked fishery products, excluding bivalve molluscs. In addition, the categories of concentration of PAH are considered a minimally contaminated and not contaminated compared with international recommended levels.

\section{References}

1. CCFAC (2005) Discussion paper on polycyclic aromatic hydrocarbons contamination. The Hague, The Netherlands.

2. Moret S, Purcaro G, Conte LS (2005) Polycyclic aromatic hydrocarbons in vegetable oils from canned foods. Eur J Lipid Sci Technol 107: 488-496.

3. Yurchenko S, Mölder U (2005) The determination of polycyclic aromatic hydrocarbons in smoked fish by gas chromatography mass spectrometry with positive-ion chemical ionization. J Food Comp Anal 18: 857-869.

4. Duedahl-Olesen L, White S, Binderup ML (2006) Polycyclic aromatic hydrocarbons $(\mathrm{PAH})$ in Danish smoked fish and meat products. Polycycl Aromat Comp 26: 163-184.

5. Stumpe-Viksna I, Bartkevics V, Kuka' re A, Morozovs A (2008) Polycyclic aromatic hydrocarbons in meat smoked with different types of wood. Food Chem 110: 794-797.

6. European Food Safety Authority EFSA (2002) Scientific Committee on Food Opinion on the risks to human health of polycyclic aromatic hydrocarbons in food, Italy.

7. ATSDR (1995) Toxicological profile for polyaromatic hydrocarbons-update. US Department of Health and Human Services, Atlanta, GA.

8. Forsberg ND, Wilson GR, Anderson KA (2011) Determination of parent and substituted polycyclic aromatic hydrocarbons in high-fat salmon using a modified QuEChERS extraction, dispersive SPE and GC-MS. J Agric Food Chem 10: 8108-8116.

9. Smoker M, Tran K, Smith RE (2010) Determination of polycyclic aromatic hydrocarbons (pahs) in shrimp. J Agric Food Chem 58: 12101-12104.

10. Khorshid M, Souaya ER, Hamzawy AH, Mohammed MN (2015) QuEChERS method followed by solid phase extraction method for gas chromatographic mass spectrometric determination of polycyclic aromatic hydrocarbons in fish. Int J Analytical Chem 7: 205-217.

11. Nisbet ICT, LaGoy PK (1992) Toxic equivalency factor (TEFs) for polycyclic aromatic hydrocarbons (PAHs). Regulat Toxicol Pharmacol 16: 290-300.

12. Soares-Gomes A, Neves RL, Aucélio R, Van Der Ven PH, Pitombo FB et al. (2010) Changes and variations of polycyclic aromatic hydrocarbon concentrations in fish, barnacles and crabs following an oil spill in a mangrove of Guanabara bay Southeast Brazil. Mar Pollut Bull 60: 1359-1363.

13. Mohammadi A, Ghasemzadeh-Mohammadi V, Haratian P, Khaksar R, Chaich M (2013) Determination of polycyclic aromatic hydrocarbons in smoked fish samples by a new microextraction technique and method optimisation using response surface methodology. J Food Chem 141: 2459-2465

14. OJEU (2011) Commission regulation (EU) No 835/2011 of 19 August 2011 
Citation: Hafez NE, Awad AM, Ibrahim SM, Mohamed HR (2017) Safety Assessment of Polycyclic Aromatic Hydrocarbons (PAHs) in Cold Smoked Fish (Mugil Cephalus) Using GC-MS. J Food Process Technol 8: 688. doi: 10.4172/2157-7110.1000688

Amending Regulation (EC) No $1881 / 2006$ as regards maximum levels for polycyclic aromatic hydrocarbons in foodstuffs.

15. El-Lahamy AA, Khalil IK, El-Sherif SA, Awad AM (2016) The influence of smoking method on the levels of poly cyclic aromatic hydrocarbons (PAHs) in smoked catfish (Clarias gariepinus) fillets. Int J Adv Res 4: 1529-1538.

16. Budzinski H, Jones I, Bellocq J, Pierard C, Garrigues P (1997) Evaluation of sediment contamination by polycyclic aromatic hydrocarbons in the Gironde estuary. Marine Chem 58: 85-97.

17. Zhang HB, Luo YM, Wong MH, Zhao QG, Zhang GL (2006) Distributions and concentrations of PAHs in Hong Kong Soils. Environ Pollut 141: 107-114.

18. Pies C, Hoffmann B, Petrowsky J, Yang Y, Ternes TA (2008) Characterization and source identification of polycyclic aromatic hydrocarbons (PAHs) in rive bank soils. Chemosphere 72: 1594-1601.

19. Placha D, Raclavska H, Matysek D, Rummeli MH (2009) The polycyclic aromatichydrocarbon concentrations in soils in the region of Valasske Mezirici, the Czech Republic. Geochem Transact 10: 12.

20. Phillips DH (1999) Polycyclic aromatic hydrocarbons in the diet. Mutation Res 443: $139-147$

21. Kazerouni N, Sinha R, Hsu CH, Greenberg A, Rothman N (2001) Analysis of 200 food items for benzo(a)pyrene and estimation of its intake in an epidemiologic study. Food Chem Toxicol 39: 423-436.

22. Yin $C Q$, Jiang $X$, Yang $X L$, Bian YR, Wang $F$ (2008) Polycyclic aromatic hydrocarbons in soils in the vicinity of Nanjing, China. Chemospher 73: 389-394. 